\section{JURNAL ABDIMAS

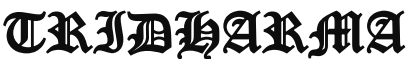

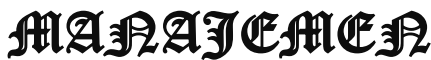

P-ISSN 0000-0000 , E-ISSN 0000-0000

Jurnal ABDIMAS Vol. 1,No.1, Agustus 2019, Hal (92-101)

@Prodi Manajemen Fakultas Ekonomi Universitas Pamulang

Email: abdimasjurnal.unpam@gmail.com Telp: (021) 741-2566

\title{
MANAJEMEN WAKTU DALAM PENGGUNAAN HANDPHONE PADA ANAK USIA REMAJA YAYASAN AL MUBAROK
}

Krisnaldy, Gos Ishak, Gatut Drajad Purwoko, Sutiman

Dosen Ekonomi Fakultas Ekonomi Universitas Pamulang

Email krisnaldyunpam@gmail.com,Gos_ishak@yahoo.com, Dosen00612@unpam.ac.id,Dosen01673@unpam.ac.id

\begin{abstract}
ABSTRAK
Pengabdian ini berjudul Manajemen Waktu dalam penggunaan Handphone pada anak usia remaja di Yayasan Al MubarokTangerang Selatan. Tujuan pengabdian ini adalah untuk Membantu memberikan arahan terhadap remaja dan anak usia dini dalam memperhatikan dalam penggunaan handphone atau gadget lainnya disela sela tugas mereka sebagai pelajar. Sehingga mereka bisa menjalani kehidupan yang lebih baik.

Metode pelaksanaan pengabdian ini dilakukan dalam beberapa kegiatan yaitu tahap survei yaitu sosialisasi dilakukan dengan menyusun berbagai hal yang akan disampaikan pada saat kegiatan pengabdian yang akan dilakukan yang meliputi: penyusunan materi yang akan diberikan, penyusunan jadwal pemberian materi, pembagian tugas tim pengabdian dan survei ke lokasi pengabdian. Tahap sosialisasi yaitu sebelum kegiatan pengabdian dilaksanakan terlebih dahulu dilakukan tahap sosialisasi yaitu melakukan silaturahmi dengan ketua yayasan, menyampaikan maksud dan tujuan pengabdian ini. Pada tahap ini juga dilakukan jalinan kerjasama dan menentukan jadwal kegiatan pengabdian. Tim pelaksana kegiatan pengabdian pada masyarakat adalah dosen Fakultas Ekonomi jurusan manajemen sebanyak 11 orang.

Kesimpulan dari pengabdian ini adalah Peserta kurang mengerti apa itu dan bagaimana mengggunakan handphone secara bijak tanpa menggangu jam belajar mengajar mereka. Harapan kami dengan pengabdian ini dapat membuka wawasan masyarakat yang diperoleh adalah bertambahnya keilmuan bagi para Para Masyarakat tentang penggunaan handphone dan gadget lainnya sehingga para remaja dapat mengatur waktu dengan baik.dan Ilmu yang diperoleh pada Pengabdian Masyarakat kali ini diharapkan mampu memberikan semangat baru bagi kita dalam menyampaikan materi dan motivasi serta berkontribusi bagi generasi muda, baik dilingkungan sekolah, kampus dan keluarga
\end{abstract}

Kata Kunci: Manajemen Waktu, Penggunaan Gadget, Handphone, Remaja 


\section{JURNAL ABDIMAS

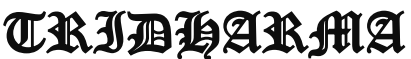

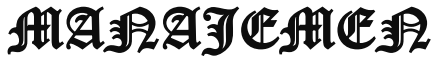

P-ISSN 0000-0000, E-ISSN 0000-0000

Jurnal ABDIMAS Vol. 1,No.1, Agustus 2019, Hal (92-101)

@Prodi Manajemen Fakultas Ekonomi Universitas Pamulang

Email: abdimasjurnal.unpam@ gmail.com Telp: (021) 741-2566

\begin{abstract}
ABSTRAC
This dedication is titled Time Management in the use of mobile phones for adolescents at the $\mathrm{Al}$ Mubarok Foundation in South Tangerang.

The purpose of this service is to help provide direction to adolescents and young children in paying attention to the use of mobile phones or other gadgets interrupted during their duties as students. So they can live a better life.

The method of implementing this service is carried out in a number of activities, namely the survey stage, namely the socialization carried out by arranging various things to be delivered at the time of service activities that will be carried out which include: preparation of material to be given, preparation of material delivery schedule, division of tasks of the service team and survey to the location devotion. The socialization phase is before the community service activities are carried out first, the socialization stage is to make a friendship with the chairman of the foundation, conveying the aims and objectives of this service. At this stage also carried out the fabric of cooperation and determine the schedule of service activities. The implementing team of community service activities are 11 lecturers at the Faculty of Economics majoring in management.

The conclusion of this dedication is that Participants do not understand what it is and how to use their cellphones wisely without disrupting their teaching and learning hours. Our hope with this dedication can open people's insights gained is the increase of knowledge for the community about the use of mobile phones and other gadgets so that teenagers can manage their time well. And the knowledge gained in Community Service this time is expected to be able to provide a new spirit for us in deliver material and motivation and contribute to the younger generation, both within the school, campus and family
\end{abstract}

\title{
Keywords: Time Management, Using, Gadget, Handphone, Teenager
}

\section{PENDAHULUAN}

Seiring perkembangan zaman, teknologi akan terus semakin canggih. Salah satunya handphone. Handphone mulanya hanya sebagai alat komunikasi jarak jauh, tapi kini fungsi handphone semakin beragam. Handphone pun kini menjadi trend. Tidak hanya orangtua saja yang mempunyai handphone, remaja bahkan anak-anak pun kini sudah mempunyai handphone. Handphone memiliki banyak kegunaan seperti alat untuk berkomunikasi (SMS/telepon), sarana memperoleh informasi, sebagai alat hitung, sebagai media untuk menyimpan data, untuk mengambil gambar maupun video, dan lain-lain. Namun disamping banyaknya kegunaan/manfaat nya, handphone juga memiliki banyak pengaruh negatif terhadap penggunanya termaksuk para remaja yang biasanya memiliki handphone hanya untuk gaya-gaya saja.Dampak negatif pada handphone paling berpengaruh pada remaja khususnya bagi pelajar. Dengan adanya fitur-fitur handphone yang canggih membuat mereka akan menghabiskan waktunya untuk bermain handphone, dan jika itu dibiarkan terus menerus 


\section{JURNAL ABDIMAS

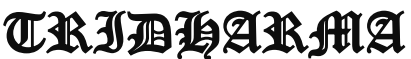

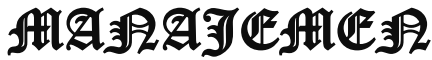

P-ISSN 0000-0000, E-ISSN 0000-0000

Jurnal ABDIMAS Vol. 1,No.1, Agustus 2019, Hal (92-101)

@Prodi Manajemen Fakultas Ekonomi Universitas Pamulang

Email: abdimasjurnal.unpam@ gmail.com Telp: (021) 741-2566 tentu akan menyita waktu belajarnya, dan membuatna menjadi pemalas. Penyalahgunaan handphone juga akan merusak moralnya sebagai seorang pelajar. Menurut penelitian, penggunaan handohone yang berlebihan tidak baik untuk kesehatan dan dapat merugikan kesehatan.

Oleh karena itu para remaja kelas harus bisa menyikapi hal tersebut mengingat banyaknya dampak yang ditimbulkan dari handphone baik itu yang positif maupun negatif. Apabila handphone disalahgunakan dipakai secara berlebihan oleh para remaja tentu akan mudah terkena dampakdampak negatif dari handphone. Namun apabila para remaja menggunakan handphone hanya untuk hal-hal yang penting (tidak berlebihan,tidak menyalahgunakan handphone) dan untuk kegiatan positif, seperti mencari informasi, memperluas dan menanbah wawasan tentu akan terhindar dari dampak-dampak negatif handphone. Jangan sampai prestasi kita hancur karena handphone.

Seiring berjalanya waktu, teknologi terus semakin canggih, orang-orang berbondong-bondong untuk terus berkarya menciptakan sebuah alat untuk memudahkan pekerjaan manusia, salah satunya handphone. Handphone diciptakan untuk memenuhi kebutuhan manusia akan komunikasi. Namun lama-kelamaan handphone menjadi gaya hidup khususnya remaja, bahkan ada beberapa yang beranggapan kalau tidak punya handphone tidak gaul. Tentu saja para remaja pastinya akan lebih mementingkan gaya hidup ketimbang belajar untuk masa depan. Merekan akan merengek kepada orang tua untuk dinelikan hp agar terlihat modern, tanpa mau mengerti keadaan ekonomi orangtuanya.
Handphone zaman sekarang sudah dilengkapi dengan fitur-fitur yang canggih. Tak bisa dipungkiri bahwa handphone memang punya beragam manfaat, tak hanya bagi orang kantoran atau orang dewasa lainnya, tapi juga bagi para pelajar.

Namun, seiring dengan perkembangan zaman, banyak pula dampak-dampak negatif handphone yang merugikan para siswa.Temanteman kelas $9 \mathrm{~h}$ pasti banyak yang telah memanfaatkan fitur-fitur yang disediakan di handphone, baik untuk kepentingan/tugas sekolah, berkomunikasi sesama teman,chatting, dan lain-lain.Namun apakah kalian menyadari bahwa fitur-fitur itu ada manfaat dan juga dampak negatifnya terhadap presrasi belajar?

Berikut manfaat handphone bagi pelajar :

Sebagai alat komunikasi jarak jauh, handphone menjadi andalan siswa untuk berinteraksi dengan temantemannya. Hal ini bisa mempermudah siswa untuk mengkoordinasi temantemannya bila ingin belajar kelompok atau mengerjakan tugas bersama.

Handphone diciptakan untuk memudahkan kehidupan, dan sudah terbukti bahwa hidup siswa pun memang cukup terbantu oleh keberadaan handphone. Misalnya, di luar jam sekolah, siswa bisa berkomunikasi dengan temannya untuk menanyakan materi tugas atau PR tanpa harus keluar rumah yang bisa menghabiskan banyak waktu.

Handphone bisa menyimpan suatu data dan mudah dibawa kemana-mana, ini tentu sangat berguna. Manfaat handphone bagi siswa berdasarkan hal ini misalnya siswa bisa mencatat materi pelajaran dan bisa menghapalnya di mana pun dan kapan pun. 


\section{JURNAL ABDIMAS

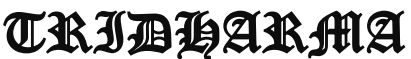

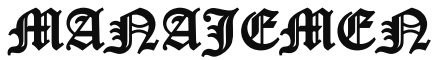

P-ISSN 0000-0000, E-ISSN 0000-0000

Jurnal ABDIMAS Vol. 1,No.1, Agustus 2019, Hal (92-101)

@Prodi Manajemen Fakultas Ekonomi Universitas Pamulang

Email: abdimasjurnal.unpam@ gmail.com Telp: (021) 741-2566
Contoh lain, siswa mencatat beberapa informasi penting dan menyimpannya dalam HP, misal pengumuman ujian, suatu materi yang ia lihat di sebuah buku di toko buku, dll.

Pengaruh handphone terhadap prestasi belajar siswa tak hanya dalam bidang pelajaran. Handphone memiliki fiturfitur hiburan, seperti musik (MP3) atau game. Fitur ini bisa menghibur para siswa yang mungkin penat saat belajar. Dengan demikian otak siswa akan kembali segar dan mampu menampung materi pelajaran dengan baik.

Saat ini telah banyak diproduksi handphone berfitur internet. Hal ini cukup memudahkan para siswa untuk mencari informasi tentang materi pelajaran lewat internet yang sudah tersedia di handphone.

Namun ada juga dampak negatif dari handphone bagi pelajar antara lain :

Hal negatif handphone yang mungkin paling menonjol adalah fitur internetnya. Walau memudahkan siswa untuk mencari informasi pelajaran, pada kenyataannya hampir semua siswa menggunakan fitur ini untuk hiburan semata. Apakah itu adalah hal yang salah? Tentu saja tidak, asalkan digunakan sesuai kapasitas. Namun faktanya, cukup banyak prestasi siswa yang menurun hanya karena terlalu asyik dengan dunia maya yang ada dalam $\mathrm{HP}$, misal asyik dengan jejaring sosial yang kini sedang marak.

Selain fitur internet, fitur game dalam HP pun cukup mempengaruhi prestasi belajar siswa di sekolah. Sama seperti internet, game tidak akan merugikan bila digunakan sesuai aturan dan memiliki batasan. Tapi, umumnya siswa malah keasyikan bermain game dan lupa untuk belajar.
Hal negatif lain adalah penggunaan handphone di saat ujian. Hal seperti ini sudah sering sekali ditemukan di sekolah-sekolah Indonesia. Keberadaan handphone yang digunakan untuk mencontek, mungkin memang akan meningkatkan nilai ujian, tapi akan sangat memperburuk mental siswa. Mereka menjadi selalu tergantung pada teman atau pada contekan yang disiapkan di dalam HP. Bila nilai bagus tidak seiring dengan kecerdasan, hal ini sangat merugikan sekali, bukan?

\section{$\square \quad$ Penggunaan dan maanfaat}

\section{handphone dalam pendidikan}

Temologi semakin berkembang, begitupun dengan pendidikan Handphone bukan hanya sekedar alat komunikasi lagi, fungsi handphone kini sudah beragam, salah satunya dibidang pendidikan.Para siswa kelas 9hsudah banyak yang memanfaatkan handphone untuk kepentingan/tugas sekolah/lainlain, bukan hanya siswanya saja tapi guru-guru pun banyak yang memanfaatkan handphone untuk kepentingan sekolah, pendidikan, dan lain-lain.

Berikut beberapa contoh penggunan handphone dalam pendidikan :

Sebagai alat hitung (menggantikan kalkulator).

Sebagai alat bantu menterjemah bahasa secara digital.

Sebagai sarana bimbingan siswa ( sms mengingatkan siswa untuk mengerjakan PR,untuk saatnya belajar, dsb)

Sebagai alat mengambil gambar/foto untuk bahan belajar.

Sebagai alat permainan perburuan kosa kata bahasa secara digital.

Ponsel kini bisa disamakan dengan komputer kecil - bisa mengecek email, melakukan pencarian on-line, dan merekam podcast. Sementara 


\section{JURNAL ABDIMAS

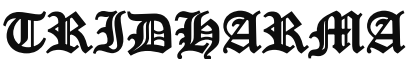

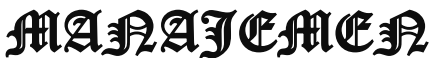

P-ISSN 0000-0000, E-ISSN 0000-0000

Jurnal ABDIMAS Vol. 1,No.1, Agustus 2019, Hal (92-101)

@Prodi Manajemen Fakultas Ekonomi Universitas Pamulang

Email: abdimasjurnal.unpam@ gmail.com Telp: (021) 741-2566 kebanyakan sekolah di daerah tak mampu memberikan komputer untuk tiap murid. Ponsel menjadi salah satu alternative.

Para guru bisa membuat blog (web log, catatan di situs internet) lewat ponsel.

Para siswa bisa mencari informasi pembelajaran di internet lewat ponsel.

Para siswa bisa melakukan riset lewat SMS atau internet di ponsel

Para siswa bisa memakai kamera ponsel untuk mengambil foto dan memasukkannya pada tugas sekolah.

\section{$\square \quad$ Upaya-upaya yang harus} dilakukan agar pelajar tidak menyalahgunakan handphone sekolah.

Melarang siswa membawa hp ke

Hal ini dilakukan agar pada saat jam pelajaran siswa fokus dengan materi yang disampaikan oleh guru, bukan hp.

Memperketat pengawasan terhadap siswa yang membawa ponsel ke sekolah.

Misalnya bapak/ibu guru bisa melakukan razia mendadak kepada siswa yang membawa hp ke sekolah. Hal tersebut bertujuan untuk meningkatkan kedisiplinan siswa.

Meningkatkan 'imunitas' siswa terhadap pengaruh buruk dari handphone maupun lingkungan sekitar melalui pendidikan agama yang berkarakter. sehat.

Mengajarka cara berinternet yang

Jadikan handphone sebagai
media untuk menyalurkan
hobi/menambah wawasan
Meningkatkan kepedulian
orangtua dan masyarakat.
Meningkatkan kesadaran para
siswa tentang efek negatif dari
penyalahgunaan handphon

\section{RUMUSAN MASALAH}

Dengan mempertimbangkan latar belakang yang telah diutarakan diatas kami berinisiatif untuk membentuk pengabdian masyarakat dengan bentuk penyuluhan mengenai Manajemen Waktu dalam penggunaan Handphone kepada Anak Usia Remaja

\section{TUJUAN PROGRAM}

1.Membantu memberikan arahan kepada anak usia remaja

2.Memberikan semangat dan motivasi bagi kepada para remaja untuk dapat mengatur waktu dalam penggunaan handphone

\section{TINJAUAN PUSTAKA}

\section{Pengertian Manajemen}

Pengertian manajemen secara umum dapat disimpulkan dari beberapa definisi menurut para ahli. Hal ini karena ada banyak versi definisi manajemen. Misalnya saja manajemen menurut seorang ahli bernama Mary Parker Follet yang mendefinisikan manajemen sebagai seni merampungkan pekerjaan melalui orang lain. Dari definisi tersebut didapati bahwa seseorang yang bertugas sebagai manajer dapat mengarahkan dan mengatur orang lain guna mencapai tujuan organisasi.

Di sisi lain, James A.F Stoner mendefinisikan manajemen sebagai proses pengorganisasian, perencanaan, dan penggunaan SDM supaya 


\section{JURNAL ABDIMAS

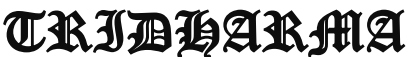

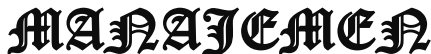

P-ISSN 0000-0000, E-ISSN 0000-0000

Jurnal ABDIMAS Vol. 1,No.1, Agustus 2019, Hal (92-101)

@Prodi Manajemen Fakultas Ekonomi Universitas Pamulang

Email: abdimasjurnal.unpam@ gmail.com Telp: (021) 741-2566 mencapai tujuan organisasi yang sudah ditetapkan.Secara umum, pengertian manajemen merupakan suatu seni dalam ilmu dan pengorganisasian seperti menyusun perencanaan, membangun organisasi dan pengorganisasiannya, pergerakan, serta pengendalian atau pengawasan. Bisa juga diartikan bahwa manajemen merupakan suatu ilmu pengetahuan yang sistematis agar dapat memahami mengapa dan bagaimana manusia saling bekerja sama agar dapat menghasilkan sesuatu yang bermanfaat bagi orang lain maupun golongan tertentu dan masyarakat luas.

Secara etimologis, pengertian manajemen merupakan seni untuk melaksanakan dan mengatur. Manajemen ini juga dilihat sebagai ilmu yang mengajarkan proses mendapatkan tujuan dalam organisasi, sebagai usaha bersama dengan beberapa orang dalam organisasi tersebut. Sehingga, ada orang yang merumuskan dan melaksanakan tindakan manajemen yang disebut dengan manajer.

\section{Fungsi Manajemen}

Pada dasarnya, fungsi manajemen dibagi menjadi tiga, yaitu:

\section{Perencanaan (planning)}

Pernecanaan adalah memikirkan apa yang akan dikerjakan dengan sumber yang dimiliki. Perencanaan dilakukan untuk menentukan tujuan perusahaan secara keseluruhan dan cara terbaik untuk memenuhi tujuan itu. Manajer mengevaluasi berbagai rencana alternatif sebelum mengambil tindakan dan kemudian melihat apakah rencana yang dipilih cocok dan dapat digunakan untuk memenuhi tujuan perusahaan. Perencanaan merupakan proses terpenting dari semua fungsi manajemen karena tanpa perencanaan, fungsi-fungsi lainnya tak dapat berjalan.

\section{Pengorganisasian (organizing)}

Pengorganisasian dilakukan dengan tujuan membagi suatu kegiatan besar menjadi kegiatan-kegiatan yang lebih kecil. Pengorganisasian mempermudah manajer dalam melakukan pengawasan dan menentukan orang yang dibutuhkan untuk melaksanakan tugastugas yang telah dibagi-bagi tersebut. Pengorganisasian dapat dilakukan dengan cara menentukan tugas apa yang harus dikerjakan, siapa yang harus mengerjakannya, bagaimana tugas-tugas tersebut dikelompokkan, siapa yang bertanggung jawab atas tugas tersebut, dan pada tingkatan mana keputusan harus diambil.

\section{Pengarahan (directing)}

Pengarahan adalah suatu tindakan untuk mengusahakan agar semua anggota kelompok berusaha agar dapat mencapai sasaran sesuai dengan perencanaan manajerial dan usaha.

\section{UNSUR-UNSUR MANAJEMEN}

Setiap perusahaan memiliki unsurunsur untuk membentuk sistem 


\section{JURNAL ABDIMAS

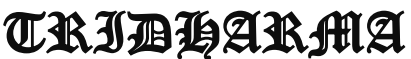

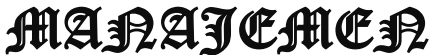

P-ISSN 0000-0000, E-ISSN 0000-0000

Jurnal ABDIMAS Vol. 1,No.1, Agustus 2019, Hal (92-101)

@ Prodi Manajemen Fakultas Ekonomi Universitas Pamulang

Email: abdimasjurnal.unpam@ gmail.com Telp: (021) 741-2566 manajerial yang baik. Unsur-unsur inilah yang disebut unsur manajemen. Jika salah satu diantaranya tidak sempurna atau tidak ada, maka akan berimbas dengan berkurangnya upaya untuk mencapai

\section{TINJAUAN PUSTAKA}

\section{Pengertian}

Manajemen

\section{Sumber Daya Manusia}

Manajemen adalah ilmu dan seni yang megatur proses pemanfaatan sumber daya manusia dan sumbersumber daya lainya secara efektif dan efesien untuk mencapai suatu tujuan tertentu.

Manajemen sumber daya manusia merupakan bagian dari ilmu manajemen yang memfokuskan perhatianya pada pengaturan peranan sumber daya manusia dalam kegiatan organisasi. Hal ini dikarnakan dalam mencapai tujuanya, organisasi memerlukan sumber daya manusia sebagai pengeelola sistemnya, dan agar sistem ini berjalan, dalam pengelolaanya diperlukan beberapa aspek penting, seprti pelatihan, pengembangan, motivasi dan aspekaspek lainya. Hal ini yang menjadikan manajeman sumber daya manusia sebagai salah satu indikator penting pencapaian tujuan organisasi secara efektif dan efisien.( mila badriah, S.E.,M.M, 15: 2015).

Manusia selalu berperan aktif dan dominan dalam kegiatan organisasi karena manusia menjadi perencana, pelaku, dan penentu terwujudanya tujuan organisasi. Tujuan tidak mungkin terwujud tanpa peran aktif tanpa peran karyawan meskipun alat- alat yang dimiliki oleh perusahaan begitu canggih. Alat-alat canggih perusahaan tidak ada manfaatnya bagi perusahaan, jika peran aktif karyawan tidak di ikut sertakan. Mengatur karyawan merupakan hal yang sulit dan kompleks karena mereka mempunyai pikiran, perasaan, status, keinginan, dan latar belakang yang heterogen yang dibawa kedalam suatu organisasi. Karyawan tidak dapat di atur dan dikuasai sepenuhnya seperti mengatur mesin, moda, dan gedung.

Manajemen sumber daya manusia merupakan bagian dari manajemen. Oleh karna itu, teori-teori manajemen umum manjadi dasar pembahasaannya mengenai pengaturan peranaan manusia dalam menentukan tujuan yang optimal.

Pengaturan itu meliputi masalah perencanaan (human resources planning),

pengorganisasian,pengarahaan,kompen asasi,pengintregrasian,pemeliharaan,ke disiplinan dan pemberhentian tenaga kerja untuk membantu terwujudnya tujuan perusahaan, karyawan, dan masyarakat.

Pengertian manajeman sumber daya manusia menurut malyu S.P. hasibuan ( 2005: 10 ) yang menyatakan bahwa :

"manajeman sumber daya manusia adalah ilmu dan seni yang mengatur hubungan dan peranan tenaga kerja yang efektif dan efisien membantu terwujudnya tujuan perusahaan, karyawan, dan masyarakat".

\section{METODE PELAKSANAAN}

Metodepelaksanaan pengabdian ini dilakukan dalam beberapa kegiatan 


\section{JURNAL ABDIMAS

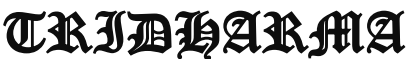

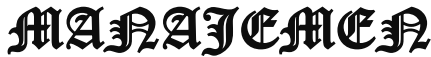

P-ISSN 0000-0000 , E-ISSN 0000-0000

Jurnal ABDIMAS Vol. 1,No.1, Agustus 2019, Hal (92-101)

@Prodi Manajemen Fakultas Ekonomi Universitas Pamulang

Email: abdimasjurnal.unpam@ gmail.com Telp: (021) 741-2566 yaitu tahap survei yaitu sosialisasi dilakukan dengan menyusun berbagai hal yang akan disampaikan pada saat kegiatan pengabdian yang akan dilakukan yang meliputi: penyusunan materi yang akan diberikan, penyusunan jadwal pemberian materi, pembagian tugas tim pengabdian dan survei ke lokasi pengabdian. Tahap sosialisasi yaitu sebelum kegiatan pengabdian dilaksanakan terlebih dahulu dilakukan tahap sosialisasi yaitu melakukan silaturahmi dengan ketua yayasan, menyampaikan maksud dan tujuan pengabdian ini. Pada tahap ini juga dilakukan jalinan kerjasama dan menentukan jadwal kegiatan pengabdian. Tim pelaksana kegiatan pengabdian pada masyarakat adalah dosen Fakultas Ekonomi jurusan manajemen sebanyak 11 orang Metode kegiatan yang digunakan adalah kita mendatangi Lokasi Panti asuhan,oleh Dosen UNPAM yang beralamatkan di Kelurahan cipayung, Ciputat, Tangerang Selatan

\section{HASIL DAN PEMBAHASAN}

\section{Pengabdian}

Masyarakat (LPPM) Universitas Pamulang yang dilakukan oleh dosen-dosen program studi Manajemen telah berjalan dengan lancar dan mendapat sambutan hangat dari tempat pelaksanaan kegiatan ini yaitu di Aula yayasan Al Mubaraok .

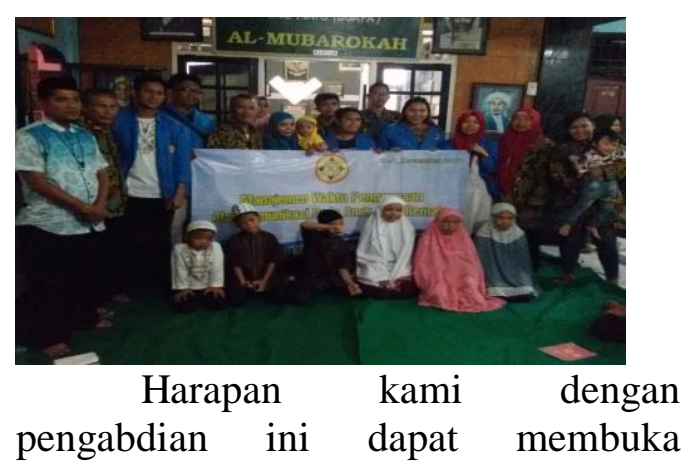

wawasan masyarakat yang diperoleh adalah bertambahnya keilmuan bagi para Para Masyarakat tentang penggunanan handphone dan gadeget di kalangan remaja dan Ilmu yang diperoleh pada Pengabdian Masyarakat kali ini diharapkan mampu memberikan semangat baru bagi kita dalam menyampaikan materi dan motivasi serta berkontribusi bagi generasi muda, baik dilingkungan sekolah, kampus dan keluarga.

\section{KESIMPULAN DAN SARAN}

Kesimpulan

Peserta kurang mengerti apa itu dampak kurang baik dari penggunaan handphone maupun gadget yang berlebihan. Peserta juga belum mengetahui bagaimana cara menghadapi tantangan dalam dunia teknologi

Saran

Setelah pengabdian ini diharapkan peserta dapat memiliki hidup yang lebih sehat secara rohani dan membangun remaja yang lebih cerdas dan intelek serta mengajak teman/peserta lainnya untuk ikut menjadi relawan dalam mencegah penggunaan hanpdhone yang berlebihan. Tim pengabdian agar terus melakukan kegiatan-kegiatan serupa secara berkesinambungan di masa yang akan datang 


\begin{tabular}{|c|c|}
\hline JURNAL ABDIMAS & P-ISSN 0000-0000 , E-ISSN 0000-0000 \\
\hline 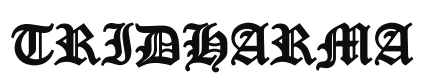 & Jurnal ABDIMAS Vol. 1,No.1, Agustus 2019, Hal (92-101) \\
\hline 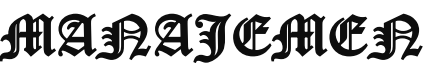 & Email: abdimasjurnal.unpam@ @mail.com Telp: (021) 741-2566 \\
\hline
\end{tabular}

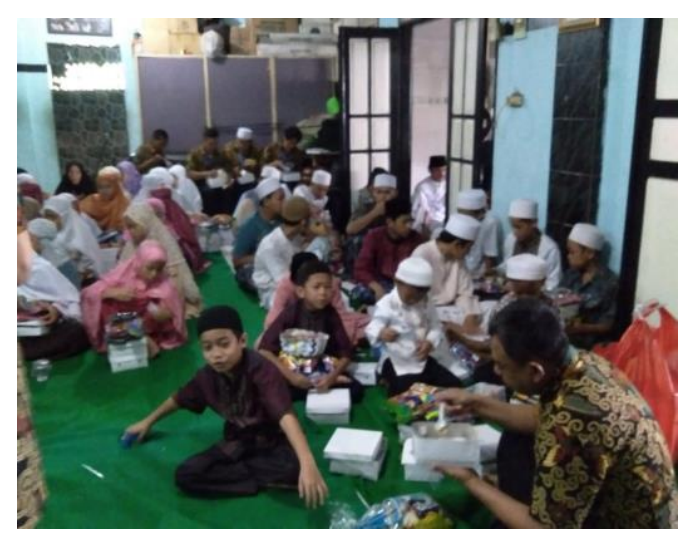

\section{DAFTAR PUSTAKA}

Hendri, Rahmi 2014.Manejemen Waktu. Jakarta: Bumi Aksara. 408 hlmn.

Kartini Kartono, 2008, Pemimpin dan kepemimpinan. Jakarta: Raja Grafindo Persada

Pasaribu, V. L. D., Susanti, F., \& Hartuti, E. T. K. (2019). MEMOTIVASI SISWA DAN SISWI SMK LETRIS INDONESIA DI DALAM MENENTUKAN PILIHAN UNTUK MELANJUTKAN PENDIDIKAN ATAU BEKERJA SETELAH LULUS SEKOLAH. Jurnal Pengabdian Dharma Laksana, 1(2), 161-172. 